\title{
An Evolutionary Algorithm for Optimal Multi-Direction Search Route in Search and Rescue Operation
}

\author{
Ngoc Ha Pham *, Minh Duc Nguyen* \\ ${ }^{\#}$ Ho Chi Minh city University of Transport, Ho Chi Minh City, Vietnam \\ E-mail: ha.pham@ut.edu.vn \\ *Vietnam Maritime University, Haiphong city, Vietnam \\ E-mail:nguyenminhduc@vimaru.edu.vn
}

\begin{abstract}
Enhancing the effectiveness of search and rescue operation at sea is the utmost importance. Once the search area has been identified, the success of search and rescue operations depends on search and rescue vessel swept the probability area of the distress object with the minimum search time, this is an important element to the success of search and rescue operation as it minimizes the risk and the cost for search and rescue team. However, determining the optimal search route to find the distress object is extremely complex because weather conditions, winds, waves, and currents always change constantly, whereas the condition of the search and rescue vessel also changes. The present article proposes the use of a bacterial foraging optimization algorithm and applies it to finding the optimal multi-direction search route for search and rescue vessel. The cost function takes into the consideration of the total search time as well as the probability of quick find of the object in distress. In this paper, the Monte Carlo simulation method is used to predict the most probable drift area of the distress object, and then a swarm of $\mathbf{1 0}$ bacteria is deployed for searching the optimal SAR route. It can be seen from the calculation result that the bacteria swarm has concentrated rather well after just several generations. The optimal search path is reasonable for the dominant weather conditions and is accordance with the popular code of practice.
\end{abstract}

Keywords—search and rescue; optimal search algorithm; BFOA; multi-direction search.

\section{INTRODUCTION}

In the developing strategy of the maritime industry, the search and rescue operation and environmental protection are considered the supporting operations but not least important [1]-[6]. In the search and rescue operation at sea, after estimating the drift area of the distress object (the search area), the minimum search time is the utmost important element to the success of the search and rescue operation as it minimizes the risk and cost for search and rescue team. Currently, the search route for a search and rescue vessel, searching for a distress object is often conducted in accordance with the instructions of the International Aeronautical and Maritime Search and Rescue (IAMSAR) manual, a manual for organization and operation of maritime and aviation search and rescue, which has been world widely used in [7], [8]. When a rescue signal is received, the search and rescue team have to determine the optimal search route based on many parameters including elapsed time, weather conditions, search devices, and units, etc. [9]-[11]. This work, if it is done manually based on IAMSAR, the common search pattern is parallel sweep search. In this search pattern, there is always one search direction and revert; it usually requires a lot of time and efforts [12]-[15]. This current instruction does not consider the efficient maneuvering of search and rescue vessel. In this urgent case, since every single minute is important, a fast and precise numerical method and algorithm, instead of the manual one, is necessary. Such a method/algorithm has still absented so far.

The bacterial foraging optimization algorithm (BFOA) is an advanced optimization technique introduced in 2002 by K.M. Passino, a professor of electrical engineering at Ohio State University (USA) [16]-[18]. Within this technique, which was originally proposed based on the social foraging behavior of the E.coli bacteria in the human intestine, a bacterium should make its foraging decision by considering two factors during its search for nutrients, namely energy consumption per unit of time and signal communications with others [19], [20]. The BFOA was developed in order to provide a fast and optimal technique to solve the above problem. Since then, this technique has been successfully applied to many fields including optimal control engineering, network scheduling, image processing, etc. [21] and has recently become one of the members of nature-inspired optimization algorithms [22]. However, it has not been 
applied to the search and rescue operation at sea, especially at the East Sea of Vietnam.

The present paper proposes using BFOA and applies it to compute the multi-direction search route for search and rescue vessel around the East Sea of Vietnam in changing the weather. As the first step, the search area is simulated by using the Monte Carlo method [23], [24]. Based on the simulated area, BFOA is then applied to find the multidirection search routes for a search and rescue vessel with minimum search time by considering the effects of ocean winds and currents and consider the efficient maneuvering of search and rescue vessel.

\section{MATERIALS AND METHODS}

As introduced in the Introduction, the BFOA, which was inspired by the bacteria forage over a landscape of nutrients, has been generally considered a promising solution for a variety of distributed optimization. The conventional BFOA consists of the following three steps. Firstly, step 1 or initialization. Initialize the population of the bacteria. Each bacterium is allocated randomly over the search space. Secondly, step 2 (Evolution). Recursively manipulate the population to gradually develop by a three-step procedure, i.e. chemotaxis and swarming, reproduction, and elimination and dispersal. Thirdly, step 3 (Termination). Return the solution accompanying with the fittest bacterium in the population.

Thus, after each above circle, the bacterial individuals will be stronger than the previous ones, i.e., bacteria are getting closer to the optimal solution of the problem. As mentioned in step 2, in nutrient foraging and evolving, bacteria population recursively goes through a process of 3 stages, namely the chemotaxis and swarming, reproduction, elimination, and dispersal. The process enables the bacteria to gradually aggregate in the most favorable region or the region of the highest concentration of the nutrient. Imitating foraging behavior of E.coli bacteria, BFOA seeks the optimum of a function through the search-space by conducting the local search through the bacteria chemotaxis, distributing local search by swarming, intensifying search in a promising region by reproduction, and avoiding traps of local optimums by elimination and dispersal.

\section{A. Chemotaxis}

Chemotaxis is the phenomenon in which bacteria, including E. coli, direct their movements according to the existence of certain chemicals in their environment. It is important for bacteria to move to areas of higher food concentration or to flee from poison. Chemotaxis is either positive or negative. In positive chemotaxis, the movement of bacteria is toward the positions of higher concentration of the chemical concerned. Conversely, negative chemotaxis causes bacteria to move away from them. The movement of bacteria is the result of alternating tumble and swim phases. These 2 phases, performed through their entire lives, direct bacteria to search for the position or region where the food concentration is richest.
Swimming is the straight run (sliding) motion of bacteria in a pre-chosen direction. It is the result of rotating their flagella counter-clockwise. In BFOA, swimming can be considered as the straight motion of a bacterium uphill, toward the position of local optimum. If the distance of swim is long, bacteria move quickly toward the optimum. However, it may also cause the search to fluctuate around this point. A small swim-distance allows the bacteria to slide slowly but steadily to a region of high nutrient concentration. The expenses accompanying with it are that it requires more time for the bacteria to reach optimum and that bacteria are incapable of jumping out of the attractive area of a local optimum.

Tumbling, on the other hand, is the turning motion of bacteria by rotating their flagella clockwise. It is the action of a bacterium to change its moving direction while seeking for food. In BFOA, it is equivalent to starting the search in a new direction. By repeatedly evaluating their course and adjusting if they are moving in the wrong direction, bacteria can direct their motion to find favorable locations with high concentrations of attractants (usual food) and avoid repellents (usually poisons):

$$
S^{i}(j+1)=S^{i}(j)+V(j) x D
$$

Where $\mathrm{i}$ : index of the bacterium in the population and $\mathrm{j}$ is a chemotactic step in a bacteria lifetime. The chemotactic $(j+1)$ is applied if the following fitness inequality is satisfied:

$$
\llbracket Q\left(S \rrbracket^{i}(j+1)\right)<Q\left(S^{i}(j)\right)+d \llbracket Q\left(S \rrbracket^{i}(j+1)\right)
$$

Where: dQ represents the total attractive/repellent force between individuals.

By repeatedly undergoing chemotactic motions, bacteria gradually climb up the hills to approach the optimums, locally or globally.

\section{B. Swarming}

Swarming is an interesting aggregation behavior of bacteria swarm. This is achieved by a primary communication mechanism between bacteria nearby.

Due to the premature structure of bacteria cells, a bacterium can exchange signal with just the bacteria nearby. The signaling scheme results in an extra factor based on which bacteria decide their chemotactic moves. Unfortunately, the mechanism behind this phenomenon is very complicated and has not yet been fully explainable. In BFOA, it is simulated by the attractive or repellent forces exerted by a bacterial cell on the other. Several parameters must be chosen to express this effect when designing BFOA. In brief, it can be simply referred to as a process in which bacteria are attracted by those within a certain range from their positions and to be repelled when the distance between them falls below a limit. If properly defined, it may help to redistribute the search in a promising local region around the optimum and draws bacteria from other regions to the most attractive region of the current search:

$$
\mathrm{dQ}\left(\mathrm{S}^{\mathrm{i}}(\mathrm{j}+1)\right)=\sum_{\mathrm{k}=1}^{\mathrm{N}_{\mathrm{s}}} \mathrm{dQ}\left(\mathrm{S}^{\mathrm{i}}(\mathrm{j}+1), \mathrm{S}^{\mathrm{h}}(\mathrm{j})\right)=\sum_{\mathrm{k}=1}^{\mathrm{N}_{\mathrm{s}}}\left[-\mathrm{d}_{\text {attract }} \exp \left(-\mathrm{w}_{\text {attract }}\left\|\mathrm{S}^{\mathrm{i}}(\mathrm{j}+1)-\mathrm{S}^{\mathrm{k}}(\mathrm{j})\right\|^{2}\right)\right]+\sum_{\mathrm{k}=1}^{\mathrm{N}_{\mathrm{s}}}\left[-\mathrm{h}_{\text {repellent }} \exp \left(-\mathrm{w}_{\text {repellent }}\left\|\mathrm{S}^{\mathrm{i}}(\mathrm{j}+1)-\mathrm{S}^{\mathrm{k}}(\mathrm{j})\right\|^{2}\right)\right]
$$


where:

$\|S\|$ : norm of vector $\mathrm{S} ; \mathrm{d}_{\text {attract }} ; \mathrm{w}_{\text {attract }} ; \mathrm{h}_{\text {repellent }} ; \mathrm{w}_{\text {repellent }}$ : coefficients representing range and magnitude attractive / repellent force between bacteria.

\section{Reproduction}

After a number of chemotactic steps, some bacteria are in regions of better nutrient content than the other. Those bacteria therefore gain more food and become stronger (i.e. healthier/longer). The healthier bacteria have more chance to reproduce. Contrarily, the less healthy bacteria will eventually die before reproducing.

In BFOA, the healthier bacteria are commonly those being in better regions of the search-space, while the weaker ones are lying in poor regions of the function values. The reproduction of healthier bacteria, therefore, increases the number of bacteria in more favorable regions to intensify the search in these regions. The number of bacteria to reproduce is chosen to be the same with a number of those who die to keep the population size unchanged. The process, therefore, increases the optimum seeking speed in more promising regions and gives up the less favorable ones.

A disadvantage of this mechanism is that bacteria which are actually in the region containing the global optimum may be killed before they can approach the optimum to gain nutrient in large volume. Accordingly, the region is, therefore, not properly searched. This must be carefully taken into consideration in designing BFOA.

\section{Elimination and Dispersal}

In nature, due to the sudden regional changes of the environment, e.g., temperature variation, several bacteria in a certain region of the search-space die. On the other hand, with favorable conditions, new bacteria arise in another region. Inspired by the phenomenon, BFOA undergoes an elimination and dispersal process in each generation.

Elimination is the act of removing bacteria. A number of bacteria except several healthiest one are selected randomly and removed from the bacteria population (elimination). They are replaced by the same number of bacteria randomly dispersed around the search region (dispersal). Thence, the total number of bacteria in the population remains unchanged. As stated above, premature convergence, or the convergence to local optimum rather than the global one, is deterrence of almost all numerical optimization methods currently in use. For BFOA, due to the randomness of the bacteria elimination and dispersal process, the possibility for every local region to be searched can be significantly increased.

The elimination and dispersal may destroy the chemotactic progress, but it also can be of help in improving the speed of chemotaxis because the bacteria may be placed in a better region of nutrient concentration. By this diversification of search, the ability for some bacteria to reach the global optimal can be significantly strengthened. In this study, an appropriate elimination scheme will be proposed to ensure that every local region has been thoroughly exploited it is abandoned.

\section{RESULTS AND DISCUSSION}

Once the search area has been identified, the success of search and rescue operations depends on the possibility of sweeping the probability area of the distress object within minimum search time. However, determining the optimal multi-search route to find the distress object in the minimum possible time is extremely complex because the weather conditions, winds, waves, and currents constantly change, whereas the condition of the search and rescue vessel also changes.

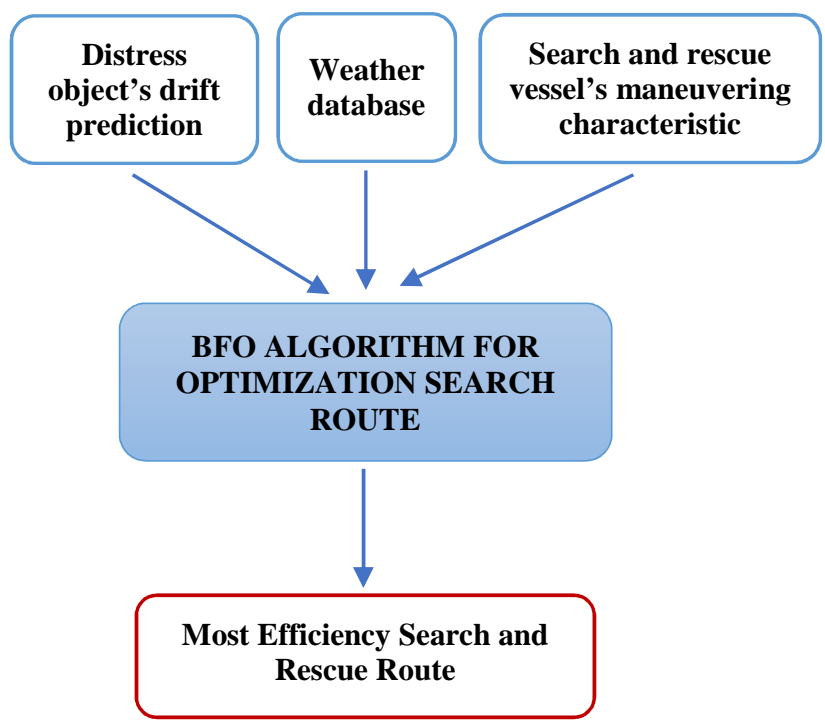

Fig. 1 Optimization search route using BFOA

\section{A. The objective function}

Bacteria definition, each search strategy is a bacterial individual. The objective function of search and rescue operation for an Engine order telegraph selected in the below formula. Engine order telegraph, which corresponding to main engine operation mode and certain propeller round per minute (RPM).

\section{Cost $=$ Total Time Search $-W x$ Total Sum of Probability}

Determining the search and rescue route is forwarded to the minimum Cost $\left(\operatorname{Cost}=\operatorname{Cost}_{\min }\right)$

- total time: the total amount of time it takes to search and rescue (with a certain speed) but less than the total time the vessel can operate (depending on fuel, weather ...)

- W: the coefficient (to give two compatible values, because the Total Sum of Probability is too small compared to Total Time Search)

- Total Sum of Probability = $\Sigma P i j$

- Pij : Probability in cell $i ; j$

- $i, j$ : cells that the search and rescue vessel sweep through during the search process.

During the search and rescue operation, the search and rescue crew (searcher) will try out the engine order telegraph (main engine modes) and select the most appropriate speed to ensure sweeping the expected area or sweep the widest 
area, with the highest probability of distress object in the minimum of time.

\section{B. BFOA algorithm diagram}

1) General flowchart for calculating the multidirectional search route for a search and rescue vessel using BFOA: Each search strategy is a bacterial individual in a set of bacteria that are considered a herd. As a general rule of BFOA, optimal search based on bacterial colonies is carried out through the steps shown in the below flowchart:

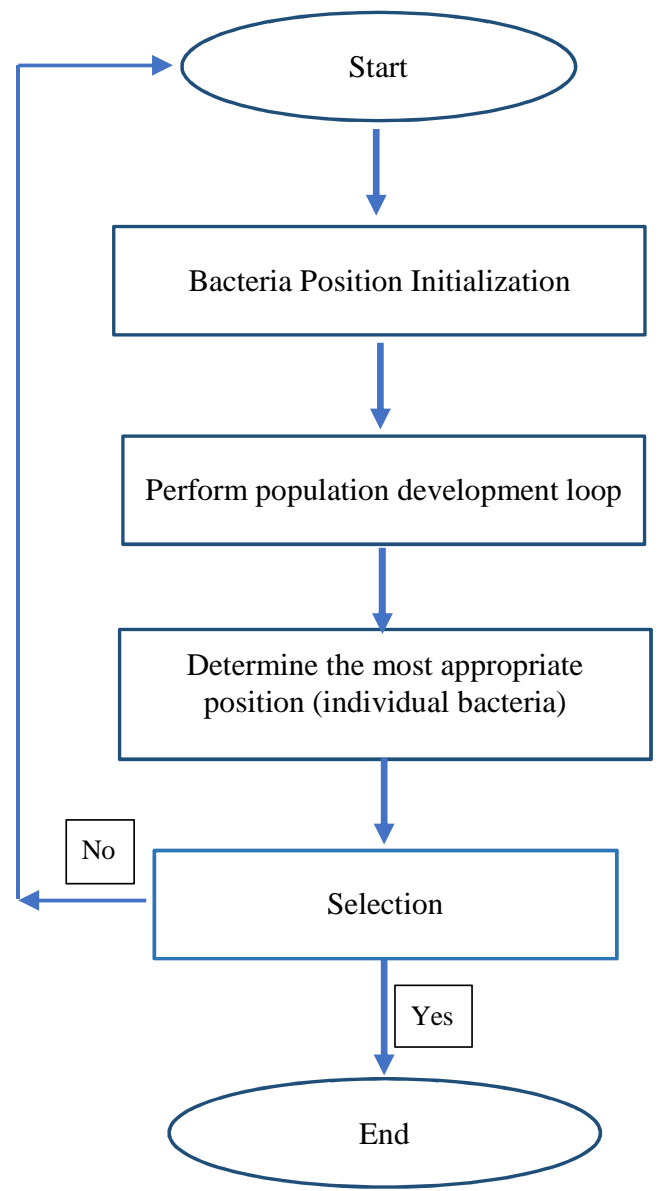

Fig. 2 BFOA flowchart for calculating the multi-directional search route

- Bacteria Position Initialization: generated randomly, each bacterium is allocated is a random creation of plans to navigate search and rescue vessel to search areas;

- Evolution: Implement population development loop: local adjustment of search plans, this step can be interpreted as loops to adjust the search plan to the optimal local area, then the search directions are become better and better by a 3-step procedure (Chemotaxis and swarming, Reproduction, Elimination, and Dispersal).

- Termination: Determining the most suitable bacterial position: After the loops have been implemented, the colonies have been converged enough and considered the optimal search result for the search and rescue vessel.

2) Loop development of bacteria generations:
Initialize a random search and rescue plan

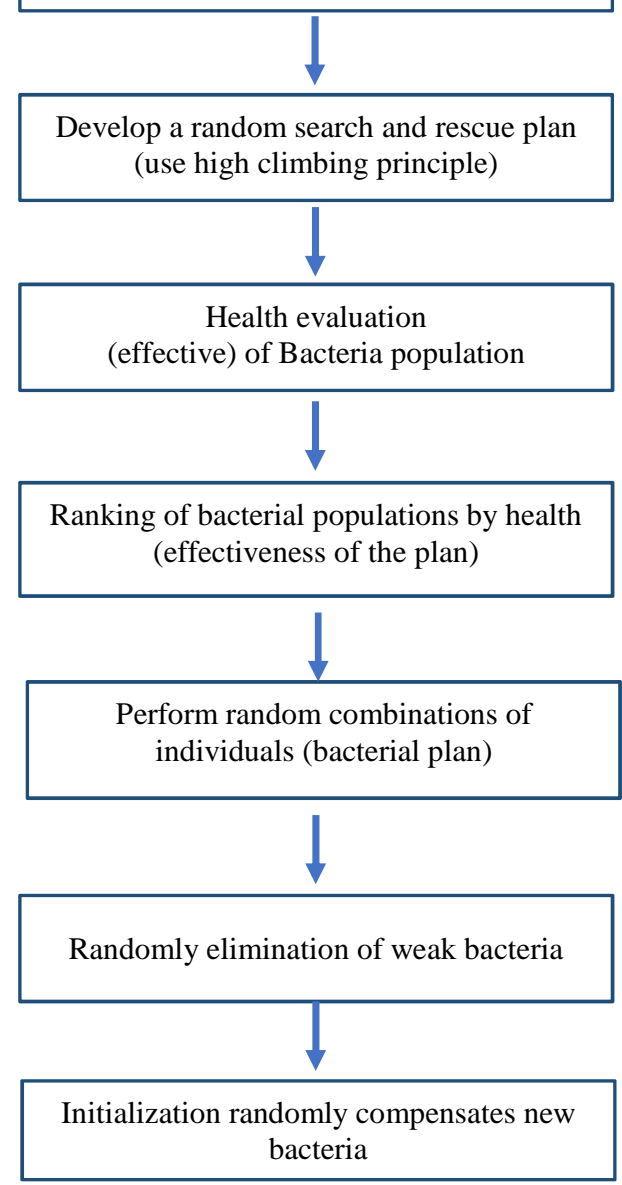

Fig. 3 Develop loop bacteria over generations flowchart

Initialize a bacterial populations. Bacteria populations is a initial random search and rescue plan. A bacteria consists of 2 parts $\{\mathrm{V} 1 ; \mathrm{V} 2\}=\{\{\mathrm{WP} 1, \mathrm{WP} 2 \ldots \mathrm{WPn}\},\{\mathrm{C} 1, \mathrm{C} 2 \ldots \mathrm{Cn}\}\}$

- V1: A set of WayPoints for search and rescue vessel to proceed the search area.

$$
V_{l}=\left\{W P_{1}, W P_{2}, \ldots W P_{n}\right\}
$$

- $\mathrm{V}_{2}$ : set of consecutive search and rescue directions in the search area.

$$
V_{2}=\left\{C_{1}, C_{2}, \ldots C_{n}\right\}
$$

Perform continuous loop evolution through bacterial generations. Improve the quality of individuals bacterial in 2 ways, i.e. select the $W P_{i}$ and $C_{i}$ randomly:

- Select the navigate direction (Dir) randomly:

- Move the WPi to the new direction: Dir WPi.Lat $=$ WPi.Lat+ Cos(Dir). $\delta$ WPi.Lon $=$ WPi.Lon+ Sin (Dir). $\delta /$ Cos.Lat

- Check the new solution, compared with the current one \{Vi new, V2\}

- Perform moving the WPi a distance $\Delta$ in the direction: Dir, if this is the better solution.

- Replace Ci with a new direction

$$
\mathrm{C}_{\mathrm{i}}=\mathrm{C}_{\mathrm{i}}+\Delta
$$

- Check the new solution $\{\mathrm{V} 1, \mathrm{~V} 2$ new $\}$

- If this is the better solution, replace $\mathrm{Ci}=\mathrm{Ci}+\Delta$ 
Pairing and reproduction of populations

- Randomly select individual father is a healthy bacteria in population $\left\{\mathrm{V}_{1}\right.$ dad, $\mathrm{V}_{2}$ dad $\}$

- Randomly selecting the mother is a healthy bacteria in the population $\left\{\mathrm{V}_{1} \mathrm{mom}, \mathrm{V}_{2} \mathrm{mom}\right\}$

- New born child has the form:

$$
\begin{gathered}
\left\{\mathrm{V}_{1 \text { dad }}, \mathrm{V}_{2 \text { dad-mom }}\right\} \\
\mathrm{V}_{2 \text { dad-mom }}=\left\{\mathrm{C}_{1 \text { dad }}, \mathrm{C}_{2 \text { dad }}, \mathrm{C}_{3 \text { mom }}, \mathrm{C}_{4 \text { mom }}\right\}
\end{gathered}
$$

Elimination and Reproduction

- Elimination: Eliminate weak bacterias.

- Reproduction: Create new random bacterias to replace discarded bacterias.

\section{Simulation results}

In the search and rescue performance, a parallel sweep search was selected for the search route. Using Visual Basic Dot NET to simulate a multi-directional search and rescue plan for the following cases:

Case 1: Person in the Water (PIW) on January 1, 2019. Last Known Position (LKP): Latitude: 10 $10^{\circ} 00^{\prime} \quad \mathrm{N}$; Longitudinal: $109^{\circ} 00^{\prime} \mathrm{E}$. The standby position of the search and rescue vessel (starting position for the search and rescue operation): $14^{0} 36^{\prime} \mathrm{N} ; 109^{0} 12^{\prime} \mathrm{E}$.

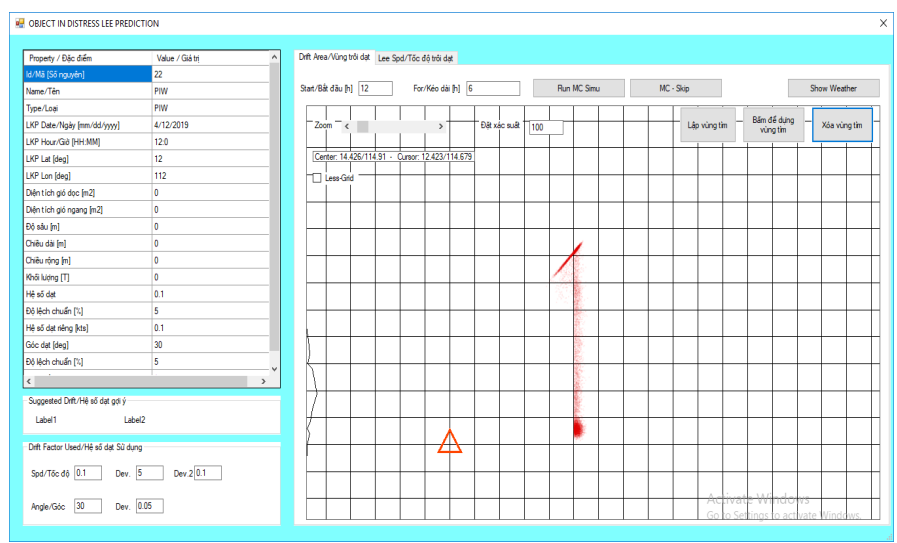

Fig. 4 Simulation of PIW drift area
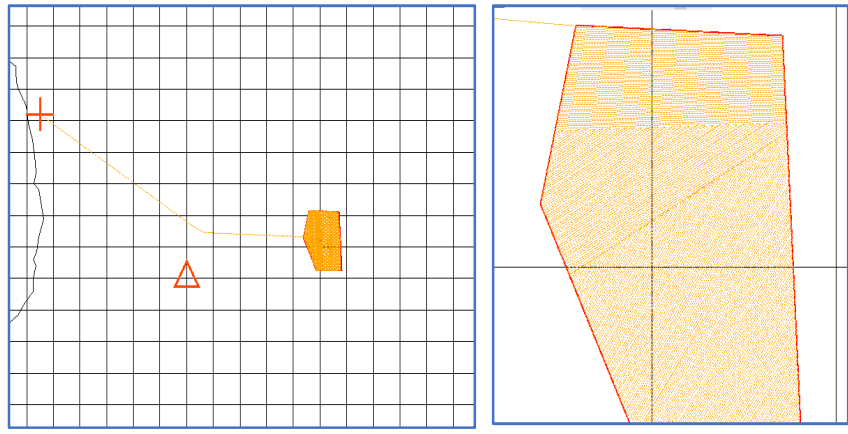

Fig. 5 An initial random search route
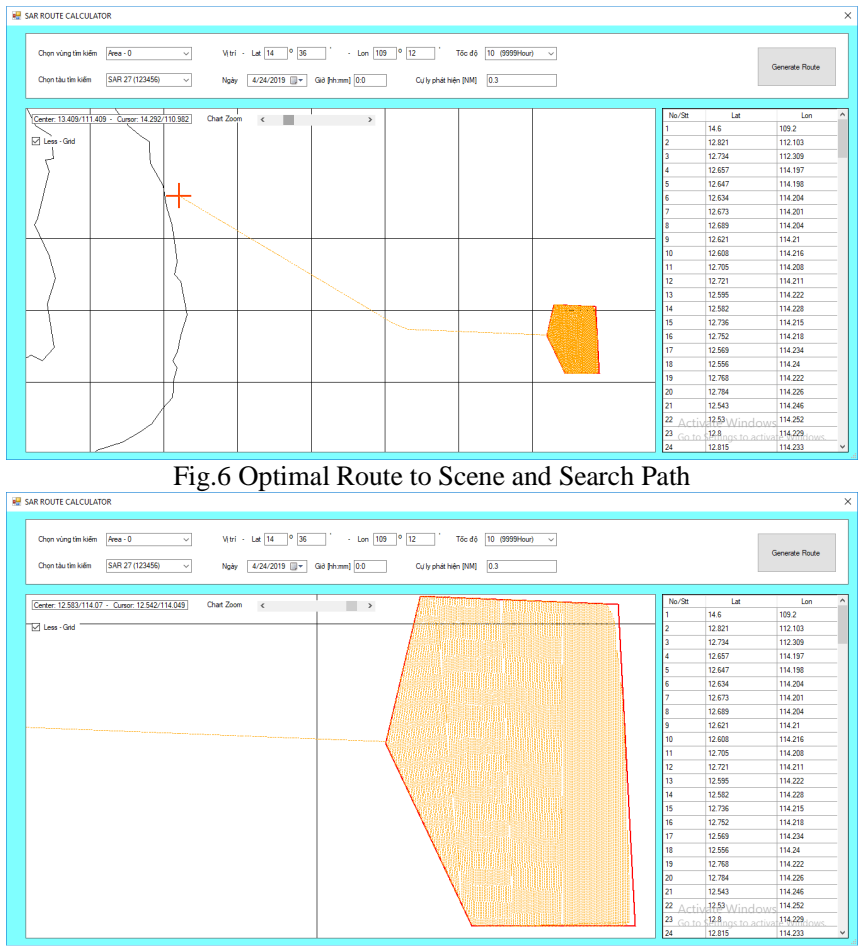

Fig.7 Detail Search Path

It can be seen from the figure that the bacteria swarm has concentrated rather well after just five generations. The optimal search path is reasonable for dominant weather conditions and is by the popular code of practice

Case 2: A Fishing Vessel with on April 12, 2019. Last Known Position (LKP): Latitude: $12^{0} 00^{\prime} \mathrm{N}$; Longitudinal: $112^{\circ} 00^{\prime} \mathrm{E}$. The standby position of the search and rescue vessel (starting position for the search and rescue operation): $12^{0} 21^{\prime} \mathrm{N} ; 109^{0} 36^{\prime} \mathrm{E}$.

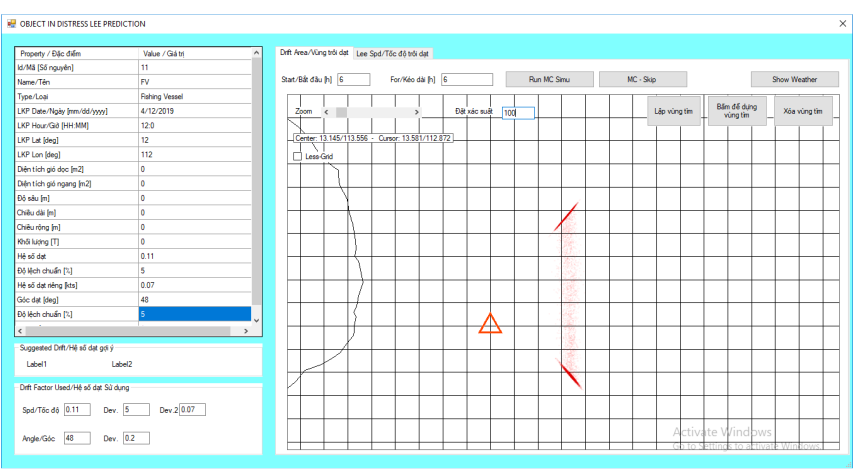

Fig. 8 Drift area of the fishing vessel in distress

It can be seen from the figure that the bacteria swarm has concentrated rather well after just five generations. The optimal search path is reasonable for dominant weather conditions and in accordance with the popular code of practice 


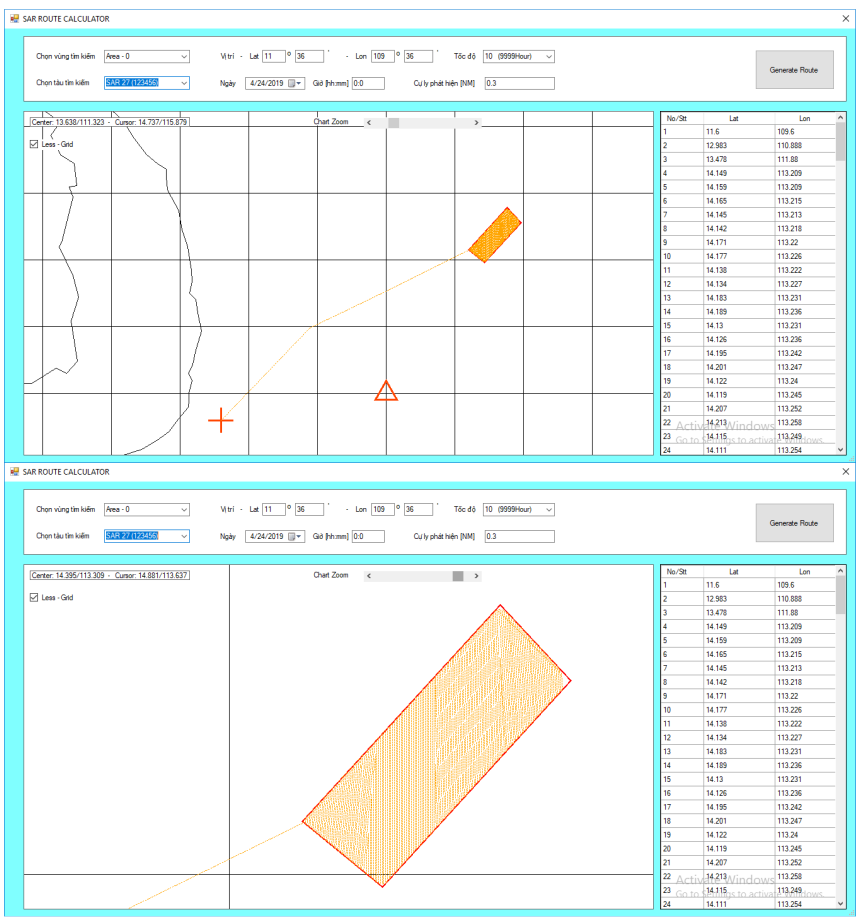

Fig. 9 Optimal Search Route as Calculated

In this case, the optimal search route has been generated within five generations and is reasonable for dominant weather conditions and by the popular code of practice.

\section{CONCLUSIONS}

The authors have developed an algorithm for optimal multi-direction search route in search and rescue operation for a search and rescue vessel strategy. Building an adapted $\mathrm{BFO}$ algorithm can be used to calculate the optimal route for multi-directional search by BFO algorithm is highly reliable, capable of calculating and giving suggestions optimal route, even in complicated weather conditions.

Determining the search area and computing optimal search options are critical to the search results. The BFOA algorithm can be applied effectively to determine and applies it to compute the optimal multi-direction search route for search and rescue vessel around the East Sea of Vietnam.

To improve the efficiency of the computation, it is necessary to study the change in the direction of the search and rescue vessel due to the weather during the search and rescue operation, and the search area is changed due to the weather also. These works will be studied by the authors shortly.

\section{REFERENCES}

[1] H. Anh Tuan and C. Minh Quang, "A mini-review of using oleophilic skimmers for oil spill recovery," J. Mech. Eng. Res. Dev., vol. 41, no. 2, pp. 92-96, 2018.

[2] A. T. Hoang and X. D. Pham, "An investigation of remediation and recovery of the oil spill and toxic heavy metal from maritime pollution by a new absorbent material,” J. Mar. Eng. Technol., 2018. https://doi.org/10.1080/20464177.2018.1544401.
[3] A. T. Hoang, "A report of the oil spill recovery and treatment technologies to reduce the marine environment pollution," Int. J. eNavigation Marit. Econ., vol. 9, pp. 35-49, 2018.

[4] A. T. Hoang, X. L. Bui, and X. D. Pham, "A novel investigation of oil and heavy metal adsorption capacity from as-fabricated adsorbent based on agricultural by-product and porous polymer," Energy Sources, Part A Recover. Util. Environ. Eff., vol. 40, no. 8, pp. 929939, 2018.

[5] A. T. Hoang et al., "An absorption capacity investigation of new absorbent based on polyurethane foams and rice straw for oil spill cleanup,” Pet. Sci. Technol., vol. 36, no. 5,pp. 361-370, 2018.

[6] Allen A A, JV Plourde, "Review of Leeway: Field Experiments and Implementation," US Coast Guard Research and Development Center, Technical Report CG-D-08-99, 1999.

[7] IMO (International Maritime Organization), International Aeronautical and Maritime Search and Rescue (IAMSAR), Volume 2, London: International Maritime Organization, 2016.

[8] IMO (International Maritime Organization), International Aeronautical and Maritime Search and Rescue (IAMSAR), Volume 3, London: International Maritime Organization, 2016.

[9] Minh Duc Nguyen, "A study on an integrated collision avoiding system for merchant ships," Doctor Thesis, Tokyo University of Marine Science and Technolgy, 2011.

[10] Jason Brownlee. 2012. Clever Algorithms: Nature-Inspired Programming Recipes. [accessed 2018 Jun 20]. http://www.cleveralgorithms.com/nature-inspired/index.html.

[11] KM Passino, "Biomimicry of bacterial foraging for distributed optimization and control," IEEE Control Systems Magazine, (Vol. 22), p.52-67, August 2002.

[12] Ngoc Ha Pham, Minh Duc Nguyen, "Summary of weather information for forecasting object drift at sea in the search and rescue operation," Journal of Marine Science and Technology, Vietnam Maritime University, No 51, p.105-110, 8/2017.

[13] Ngoc Ha Pham, Minh Duc Nguyen, "Weather Data Analysis and Drift Object Estimation by Monte Carlo Simulation for Vietnam's East Sea," in Proc. Asia Maritime \& Fisheries Universities Forum (AMFUF), 2017, p.467-477.

[14] Vipul Sharma, SS Pattnaik, Tanuj Garg, "A Review of Bacterial Foraging Optimization and Its Applications," National Conference on Future Aspects of Artificial intelligence in Industrial Automation, in Proceedings of the NCFAAIIA, p 09-12, May 2012.

[15] Alexey Bezgodov; Dmitrii Esin, "Complex Network Modeling For Maritime Search and Rescue Operations," Procedia Computer Science Volume 29, 2014, Pages 2325-2335;

[16] C. Ying et al., "A Fast Bacterial Swarming Algorithm for highdimensional function optimization", IEEE World Congress on Computational Intelligence, pp. 3135-3140, 2008

[17] H. Chen, Y. Zhu, K. Hu, "Adaptive Bacterial Foraging Optimization", available "http://www.hindawi.com/journals/aaa/2011/108269/"

[18] M.D. Nguyen et al, Multi-Scale Automatic Route Planning Algorithms for Sea-Going Vessel, AMFUF 2013.

[19] M.D. Nguyen et al, Automatic collision avoiding system for ship in congested water and at open sea, ICAIS 2012.

[20] M.D. Nguyen et al, "A study on An Automatic Navigation System Basing on Radar and AIS data," World Congress 2009 International Association of Institute of Naviation, 2009.

[21] M. Tripathy, S. Mishra, et al., "Transmission loss reduction based on FACTS and bacteria foraging algorithm," Proceedings of the 9th International Conference on Parallel Problem Solving from Nature (PPSN '06), Vol. 4193 , pp. 222-231, 2006;

[22] Liu Hongdan, et al., "Ship Collision Avoidance Path Planning Strategy Based on Quantum Bacterial Foraging Algorithm", Proceedings of the 2nd International Conference on Electrical, Computer Engineering and Electronics (ICECEE 2015) p.612-621;

[23] S. Mishra, "A hybrid least square-fuzzy bacterial foraging strategy for harmonic estimation," IEEE Transactions on Evolutionary Computation, Vol. 9, No. 1, pp. 61-73, 2005.

[24] Y. Liu and K. M. Passino, "Biomimicry of social foraging bacteria for distributed optimization: Models, principles, and emergent behaviors," Journal of Optimization Theory and Applications, Vol. 115, pp. 603-628, 2002. 